\title{
Research on the Cultivation of Students' Awareness of Innovation and Entrepreneurship in Medical Colleges and Universities
}

\author{
Huilin An \\ Baotou Medical College \\ Humanities and Social Science School \\ Baotou, China
}

\begin{abstract}
The training process of innovation and entrepreneurship awareness in medical colleges is very slow; the form is single, and the effect is not significant. Cultivating and improving the innovative and entrepreneurship awareness of students are important to the reform of the medical and health supply side, as well as effective means to the reform and innovation of the medical and health system in China. In order to cultivate the innovative and entrepreneurship awareness of students and improve the reform of the medical and health supply side, various measures to integrate resources of the training of innovation and entrepreneurship awareness should be taken in medical colleges and universities. Through the study of national policies carefully, the problems of awareness of students' innovation and entrepreneurship education are analyzed. Then, countermeasures are proposed. Medical colleges and universities should create a related campus environment, strength innovation and entrepreneurship education reform, and form a long-term mechanism for cultivating innovation and the platform.
\end{abstract}

Keywords-medical colleges and universities; undergraduate; innovation and entrepreneurship; awareness training; teaching reform; the pharmaceutical industry

\section{INTRODUCTION}

"Innovation" has fully been integrated into production and life, which matches the national development concept and the strategy of building an innovative country. And it was mentioned 59 times in the Report of the 19th National Congress of the Communist Party of China. The report proposes to stimulate and protect the innovation for encouraging more social subjects to engage in innovation and entrepreneurship [1]. As the most active group, college students are the reserve force of the labor force of innovation and entrepreneurship, and also the main force of economic construction and development in the future. With the popularity of all kinds of innovation and entrepreneurship competitions, more and more college students are engaged in relative projects, and the proportion of the number of selfemployed people is also rising. The integration of innovative and entrepreneurial ideas into college education is not to make all college students devote themselves to entrepreneurship after graduation, but to cultivate the students' consciousness of innovation and entrepreneurship in order to equip them with the entrepreneurial spirit required for different professional

This paper is achievements, which funded by Baotou medical college scientific research project "Research on the cultivation of students' awareness of entrepreneurship and innovation in medical colleges and universities" (project number: bysz201703). positions in the future through the university education. Therefore, strengthening the cultivation of innovation and entrepreneurship awareness in institutions of higher learning is an important measure to practice the five national development concepts led by innovation and promotion of "made in China 2025".

\section{IT IS IMPERATIVE FOR MEDICAL COLLEGES AND} UNIVERSITIES TO ESTABLISH COLLEGE STUDENTS' CONSCIOUSNESS OF INNOVATION AND ENTREPRENEURSHIP

\section{A. National policy orientation is the inevitable trend of medical college teaching reform}

In 1989, UNESCO proposed that entrepreneurship education, which was formally proposed in China in the early 1990s, would become the trend of educational reform and development. Since then, China has attached great importance to the cultivation of college students' awareness and ability of innovation and entrepreneurship and emphasized the comprehensive deepening of the education reform in colleges and universities. In 2018, the Opinions of the State Council: Promoting High-quality Development of Innovation and Entrepreneurship and Creating An Upgraded Version of "Entrepreneurship and Innovation", highlighted the need to strengthen the education and training for college students. The cultivation of innovation and entrepreneurship consciousness starts from scratch, from point to point, from pilot to promotion, and from promotion to deepening. At the institutional level, the state has made arrangements for the cultivation of innovation and entrepreneurship consciousness in colleges and universities from the top-level design. Medical colleges and universities should break the shackles of traditional educational thoughts and concepts so that they can improve the humanistic quality of students, constantly improve the quality of talents training in the medical industry, and promote the scientific development of medical education higher. 
B. To relieve the employment pressure by breaking through the shackles of traditional employment thoughts of medical college students

With the continuous popularization of higher education in medical colleges and universities, there emerges an imbalance between the supply and demand of talents, and in the two-way job market in the medical industry. The aging of the population, the complexity of the disease and the high standardization of medical management institutions make medical college graduates fail to meet the actual demand of the medical industry. First, most medical college students adhere to the traditional concept of employment and hope to work in the pharmaceutical industry after graduation. In pursuit of stable income and work, most students prefer to work in big cities and hospitals, rather than in remote areas, and seldomly consider other occupations or even start a business because of their strong sense of professional belonging, high professional loyalty and high employment expectation. Most students have firmly established the belief of being an angel in white since they entered the school, so they are not willing to give up the long-term study experience or work in grassroots health services in remote areas. Instead, they hope to enter hospitals, especially well-known hospitals in top-tier cities after graduation. Second, with the deepening of medical and health system reform, the personnel autonomy of major hospitals and medical institutions increases [2]. These institutions or institutions have a limited number of posts and significantly higher requirements on the quality of talents, making the employment of medical college graduates more optimal. Therefore, colleges themselves should carry out innovation and entrepreneurship education to cultivate the awareness, breaking away from the shackles of traditional concepts, by enriching the second classroom in college and providing more possibilities for laying the foundation of future innovation and entrepreneurship activities or employment.

\section{To expand the quality of innovation and entrepreneurship and lead the deep integration of innovation-driven health economy}

Medical college students prefer professional knowledge and scientific literacy, which leads to their negligence in improving their innovation and entrepreneurship quality that promotes their innovation ability effectively transformed into social productivity. From the perspective of input of production factors, the driving force of factors and investment scale is gradually weakening. The traditional pattern of high input, high consumption and extensive development cannot be sustained. Low-end supply and high-end demand are seriously mismatched. The medical service industry needs to be innovation-driven to increase technology supply and talent supply. Shifting gears and upgrading the economic structure played an important role. The awareness training pays attention to the cultivation of the college students' spirit value to realize the value of life. For student's comprehensive growth, here are better interpretation: talents drive innovation, further liberation and the development of medical and health undertakings, optimize the efficient allocation of health resources to improve the medical industry service level. The integration of health development with social and economic development will provide strong support for economic growth.

\section{CURRENT SITUATION OF MEDICAL COLLEGE STUDENTS’ AWARENESS IN INNOVATION AND ENTREPRENEURSHIP}

A. The traditional employment concept of college students is bound, but the consciousness of innovation and entrepreneurship is weak.

Innovation and entrepreneurship activities, with long intervals between one and another, are in simple forms and the achievements of sharing and exchanging can not be realized instantly. However, compared with college students in common universities, medical college students have a clearer career orientation, who usually continue to study further or choose to become medical workers in hospitals with stable income when graduating. In particular, medical students have a relatively long training period, strong professional knowledge, heavy daily learning tasks and little contact about innovation and entrepreneurship. For newly graduated medical students, it is difficult for them to examine and approve medical institutions, environmental assessment and business management [3]. The interdisciplinary students in medical colleges and universities are influenced by the school environment and the employment concepts so that they have little professional knowledge required for innovation and entrepreneurship in the pharmaceutical industry and they are restricted by the high-tech barriers to innovation and entrepreneurship. At the same time, students have little knowledge of other industries, so their core competitiveness of participating in innovation and entrepreneurship activities is not high, which discourages students' enthusiasm for innovation and entrepreneurship to some extent.

\section{B. Misunderstanding and insufficient attention are paid to the cultivation of innovation and entrepreneurship awareness in medical school proofreading}

The understanding of innovation and entrepreneurship education in medical school proofreading is not accurate or profound, and the cultivation of innovation and entrepreneurship awareness has not been systematic. Among the "top 50 universities for innovation and entrepreneurship" selected by the Ministry of Education in the past three years, there was one medical college in 2016 and one in 2017. They are Shandong Lianhe College and Guangxi Medical University. That accounts for a small proportion of the total number of medical colleges and universities in China. To some extent, it reflects that medical colleges and universities are not quite in place in implementing the national innovation and entrepreneurship education and teaching reform policy based on the understanding of the policy intention, during which there is a lack of overall strategic design and integrated management. Innovation and entrepreneurship courses are mechanically incorporated into talent training programs and separated from professional education. When making training plans, some colleges and universities blindly suppress the curriculum setting of innovation and entrepreneurship to the person in charge of each major. On the one hand, they are 
restricted by the professional field. On the other hand, they set the curriculum setting of innovation and entrepreneurship only to complete tasks. The quality of instructors and the reasonableness of the curriculum are not reviewed. Supporting resources for innovation and entrepreneurship are not integrated, and there is a lack of linkage among the activities, courses, mentors and laboratory management. The utilization rate of supporting facilities is low and the input funds are not in place.

\section{The system and mechanism of innovation and entrepreneurship are not sound, lacking of the cooperation platform}

Although some medical colleges and universities advocate the cultivation of innovation and entrepreneurship consciousness, there is neither the corresponding mechanism as a long-term guarantee nor the institutionalized innovation and entrepreneurship work. College students participate in innovation and entrepreneurship activities such as credit setting, quantification, assessment and graduation related various platforms of innovation and entrepreneurship, which includes setting, construction, maintenance, source, use and supervision of funds for innovation and entrepreneurship. There are a few courses or lectures related to innovation and entrepreneurship, and they are even not included in compulsory courses or professional education. Practical teaching is a mere formality and the laboratory is not open enough. What's worse, some medical colleges have not established innovation and entrepreneurship centers for their students, incubation bases or other platforms.

\section{STRATEGIES FOR CULTIVATING INNOVATIVE AND} ENTREPRENEURIAL CONSCIOUSNESS OF MEDICAL COLLEGE STUDENTS

\section{A. To firmly establish the concept of innovation and entrepreneurship education, and create a related campus environment}

To create an overall campus cultural environment for innovation and entrepreneurship, and to highlight the theme of innovation and entrepreneurship with innovation and entrepreneurship activities as the carrier, it is conducive to improve the awareness of innovation and entrepreneurship of college students and their comprehensive quality. Innovation and entrepreneurship activities not only enrich the connotation of campus culture but also fill the form and content of campus culture. It is also an important platform for medical college students to improve their humanistic quality and strengthen their ideology. Therefore, based on the classes, colleges or college students' associations, innovation and entrepreneurship activities at all levels are carried out to display the creative achievements that strengthen the exchange of ideas and content. We will make more efforts to publicize innovation and entrepreneurship content, foster students' awareness of innovation and entrepreneurship as early as possible, to encourage students to actively participate in the activities and courses, and truly experience the fun and value of creation. Medical colleges and universities should not only establish the innovation and entrepreneurship mentoring system, but also focus on students' interaction, playing the role of mentoring, and create a public opinion environment to help the purpose achieved. Through the combination of soft strength (atmosphere building and education system) and hard strength (practical activities and platforms), the awareness of innovation and entrepreneurship of medical college students should be strengthened.

\section{B. To strengthen innovation and entrepreneurship} education reform, establish and improve innovation and entrepreneurship mechanism

Medical colleges and universities integrate more ideas, courses and training objectives about innovative and entrepreneurship into the talent training program, and conduct top-level design from the goal of talent training to meet social needs. Based on the goal of cultivating the consciousness of innovation and entrepreneurship, a scientific curriculum system is established by the school. It is equipped with professional teachers for innovation and entrepreneurship to improve supporting facilities and to increase relevant funding input. Since freshmen entrance education, instill innovation concept of entrepreneurship with innovation and entrepreneurial activity as the means, class and community as the platform, combining the innovation business idea and career planning as the main channel to cultivate college students' creating innovative pioneering consciousness, set up a teaching innovation of different types of hierarchy, organize games at all levels, the skill competition, science and technology salon, learning exchange activities and so on. They have built a multilevel embedded innovation entrepreneurship education aggregation pattern. It is medical colleges and universities carrying out the creative education that pays attention to combining with the characteristics of professional and outstanding professional to establish a scientific and reasonable talent training scheme in order to develop students' basic quality for innovative undertakings and improve the rationality of the curriculum and professional innovative undertaking. We should increase investment in innovation and entrepreneurship and guide both ways to improve the quality of the instructors. It is essential to build a discipline competition system and an experimental teaching platform and to open the laboratory towards the outside world. The cultivation of innovation and entrepreneurship awareness in college can make up for the gap of students' conservative employment ideas and shape their personality traits with craftsman spirit.

\section{Form a long-term mechanism for cultivating innovation and entrepreneurship awareness and develop the platform for innovation and entrepreneurship}

Institutionalize and streamline innovation and entrepreneurship work to improve the enthusiasm of teachers and students to participate in innovation and entrepreneurship activities, and promote the formation of a long-term mechanism for cultivating the innovation and entrepreneurship awareness. We will strengthen the building of platforms for basic innovation and entrepreneurship, and make use of the developed platforms for experimental teaching demonstration bases, off-campus hospital teaching bases, virtual simulation 
teaching sites, and medical training centers. We will also set up the school educational goal and professional characteristics and the guest room, such as the college students' bases, innovation business platforms and the mechanism supporting innovation ideas to encourage the creative achievements to form and popularize, and promote the practice (experimental) teaching platform sharing. It is helpful to explore the wider, more hierarchical and collaborative innovation entrepreneurship education system.

\section{CONCLUSION}

Having further implemented the tutorial system for innovation and entrepreneurship activities, we will encourage students of all majors to participate in scientific research projects at all levels and in the innovation and entrepreneurship projects. We will build more platforms to encourage students to explore and create, in a bid to increase the number of student patent applications and patent authorization focused on the transformation of scientific research results. By means of "production", the "triple helix" model as the link, construct the political participation of cooperative innovation mechanism and make full use of the advantages of the Internet. Set up internet links between public college and government, colleges, universities and hospitals, universities and drug companies[4] to promote the cross fusion between them.

\section{REFERENCES}

[1] Xi Jinping. Determined to complete the building of a moderately prosperous society in all respects and win the great victory of socialism with Chinese characteristics for a new era [R]. Beijing: the 19th national congress of the communist party of China, 2017.

[2] Zhao Yan. Innovation Research on Entrepreneurship Education of College Students in Traditional Chinese Medicine Colleges [J]. School Party Building and Ideological Education,2014, (6): 63-69.

[3] Zhang Fengli, Huang Chibing. Analysis on the Cultivation of Innovation and Entrepreneurship among Medical College Students [J]. Journal of Fujian medical university (social science edition), 2017, 18 (2): 10-13. (in Chinese with English abstract).

[4] Zhang Zhiguo, Xue Xiaojuan. Problems and Countermeasures of Innovation and Entrepreneurship Education in Traditional Chinese Medicine Colleges and Universities[J]. Journal of Tianjin University of Traditional Chinese Medicine, 2017, (3): 223-225. 